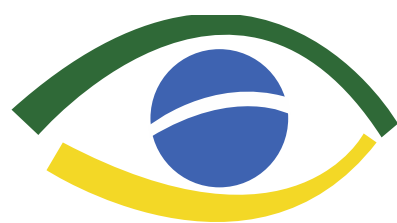

Observatório da Jurisdiçãc

Constitucional
Observatório da Jurisdição Constitucional. Ano 7, no. 1, jan./jun. 2014. ISSN 1982-4564.

\title{
Os princípios constitucionais da administração pública e a vedação do nepotismo: uma análise a partir da ADC 12-DF
}

Simone Andréa Barcelos Coutinho

Resumo: Este texto analisa, a partir do acórdão proferido na ADC 12-DF, o conteúdo de princípios constitucionais da administração pública, especialmente os da impessoalidade e da moralidade, que resultaram na vedação do nepotismo.

Palavras-chave: Direito Constitucional; Princípios constitucionais da administração pública; Direito Administrativo; Servidor público; Vedação do nepotismo.
Abstract: This paper analyzes, from the judgment of the ADC 12-DF, the content of constitutional principles of public administration, especially the impersonality and morality, which resulted in the prohibition of nepotism.

Keywords: Constitutional Law; Constitutional principles of public administration. Administrative Law; Civil Servant; Prohibition of nepotism.

\footnotetext{
* Procuradora do Município de São Paulo.
} 
Sumário: Introdução. 1. O objeto da ADC 12-DF. 2. A competência discricionária na Constituição de 1988. 3. Os princípios constitucionais da Administração Pública e o nepotismo. 3.1. O princípio da impessoalidade e o nepotismo. 3.2. O princípio da moralidade e o nepotismo. 3.3. Impessoalidade, moralidade e proibição do nepotismo. 4. A impessoalidade, a moralidade e a admissão de pessoal ao serviço público. 5. Conclusão.

\section{Introdução}

O tema-título deste estudo - os princípios constitucionais da Administração Pública e a vedação do nepotismo- comporta vasto campo de investigação, quer teórico, quer jurisprudencial. Este trabalho cingir-se-á à abordagem do tema a partir do julgamento proferido, pelo Supremo Tribunal Federal, na Ação Declaratória de Constitucionalidade $\mathrm{n}^{\mathrm{o}} 12$, proposta pela Associação dos Magistrados Brasileiros - AMB, para o fim de ver declarada a constitucionalidade da Resolução 7/2005, do Conselho Nacional de Justiça, que disciplina o exercício de cargos, empregos e funções por parentes de magistrados, no âmbito do Poder Judiciário.

A leitura atenta do acórdão resulta na observação dos seguintes pontos: a) nenhum dos votos proferidos disseca o tema da discricionariedade, ou competência discricionária, quanto ao seu conteúdo e extensão; b) nenhum dos votos debate o controle jurisdicional dos atos emanados no exercício de competência discricionária; c) os votos põem ênfase na competência do CNJ para emanar a norma cuja declaração de constitucionalidade se procura, bem como no conteúdo e eficácia dos princípios insculpidos no caput do artigo 37 da Constituição da República.

Essas observações levam à seguinte conclusão, de saída: ao julgar a $\operatorname{ADC} \mathrm{n}^{\mathbf{0}}$ 12, o Supremo Tribunal Federal considerou, quanto à matéria nela posta ao menos, irrelevantes as inquietações suscitadas pela doutrina tradicional do Direito Administrativo sobre o capítulo da discricionariedade, das quais passou ao largo naquela assentada.

Num primeiro turno, o aresto desperta importante problemática, como bem elucidou o Ministro Menezes Direito em seu voto: do alcance e da eficácia dos princípios insculpidos no artigo 37 da Constituição Federal, que, por unanimidade, o Tribunal acordou ser imediata. Isto não é pouca coisa, sobretudo se tivermos em mente o aforismo que define o princípio da legalidade para a Administração Pública - só fazer o que a lei manda. No turno final, como se verá a seguir, agregada a análise do conteúdo daqueles princípios, em especial, os da 
impessoalidade e da moralidade, os debates travados quer no acórdão que julgou o mérito da ação declaratória, quer naquele que julgou a medida cautelar, fazem acudir à mente a seguinte questão: qual o regime da competência administrativa na Constituição de 1988, no tocante à admissão de pessoal? Porém, há algumas pedras no meio do caminho; tentaremos conhecê-las melhor.

\section{O objeto da ADC 12-DF}

Tal como adiantado na introdução, a ação declaratória em foco foi proposta com vistas a ver declarada a constitucionalidade da Resolução 7/2005, do Conselho Nacional de Justiça, que disciplina o exercício de cargos, empregos e funções por parentes, cônjuges e companheiros de magistrados e de servidores investidos em cargos de direção e assessoramento, no âmbito do Poder Judiciário, e dá outras providências.

A Resolução em questão cuida de vedar o nepotismo em todos os órgãos do Poder Judiciário $\left(\operatorname{art.} 1^{\circ}\right.$ ), arrolando as práticas que o caracterizam (art. $2^{\circ}$, verbis):

Art. $2^{\circ}$ Constituem práticas de nepotismo, dentre outras: I - o exercício de cargo de provimento em comissão ou de função gratificada, no âmbito da jurisdição de cada Tribunal ou Juízo, por cônjuge, companheiro ou parente em linha reta, colateral ou por afinidade, até o terceiro grau, inclusive, dos respectivos membros ou juízes vinculados; II - o exercício, em Tribunais ou Juízos diversos, de cargos de provimento em comissão, ou de funções gratificadas, por cônjuges, companheiros ou parentes em linha reta, colateral ou por afinidade, até o terceiro grau, inclusive, de dois ou mais magistrados, ou de servidores investidos em cargos de direção ou de assessoramento, em circunstâncias que caracterizem ajuste para burlar a regra do inciso anterior mediante reciprocidade nas nomeações ou designações;

III - o exercício de cargo de provimento em comissão ou de função gratificada, no âmbito da jurisdição de cada Tribunal ou Juízo, por cônjuge, companheiro ou parente em linha reta, colateral ou por afinidade, até o terceiro grau, inclusive, de qualquer servidor investido em cargo de direção ou de assessoramento;

IV - a contratação por tempo determinado para atender a necessidade temporária de excepcional interesse público, de cônjuge, companheiro ou parente em linha reta, colateral ou por afinidade, até o terceiro grau, inclusive, dos respectivos membros ou juízes vinculados, bem como de qualquer servidor investido em cargo de direção ou de assessoramento; 
V - a contratação, em casos excepcionais de dispensa ou inexigibilidade de licitação, de pessoa jurídica da qual sejam sócios cônjuge, companheiro ou parente em linha reta ou colateral até o terceiro grau, inclusive, dos respectivos membros ou juízes vinculados, ou servidor investido em cargo de direção e de assessoramento.

$\S 1^{\circ}$ Ficam excepcionadas, nas hipóteses dos incisos I, II e III deste artigo, as nomeações ou designações de servidores ocupantes de cargo de provimento efetivo das carreiras judiciárias, admitidos por concurso público, observada a compatibilidade do grau de escolaridade do cargo de origem, ou a compatibilidade da atividade que lhe seja afeta e a complexidade inerente ao cargo em comissão a ser exercido, além da qualificação profissional do servidor, vedada, em qualquer caso, a nomeação ou designação para servir subordinado ao magistrado ou servidor determinante da incompatibilidade.

$\S 2^{\circ}$ A vedação constante do inciso IV deste artigo não se aplica quando a contratação por tempo determinado para atender a necessidade temporária de excepcional interesse público houver sido precedida de regular processo seletivo, em cumprimento de preceito legal.

Art. $3^{\circ}$ É vedada a manutenção, aditamento ou prorrogação de contrato de prestação de serviços com empresa que venha a contratar empregados que sejam cônjuges, companheiros ou parentes em linha reta, colateral ou por afinidade, até o terceiro grau, inclusive, de ocupantes de cargos de direção e de assessoramento, de membros ou juízes vinculados ao respectivo Tribunal contratante, devendo tal condição constar expressamente dos editais de licitação. (itálicos nossos).

Vê-se que as práticas que constituem o nepotismo, nos termos da Resolução 7/2005, referem-se a situações decorrentes de atos administrativos praticados no exercício de competências discricionárias: nomeação para cargos em comissão ou funções gratificadas, contratação de servidores por tempo determinado para atender a necessidade temporária de excepcional interesse público (não procedida de processo seletivo), contratação em casos excepcionais de dispensa ou inexigibilidade de licitação.

$\mathrm{O}$ acórdão proferido entendeu que os condicionamentos impostos pela Resolução discutida não atentam contra a liberdade de nomeação e exoneração dos cargos em comissão e funções de confiança, porque a interpretação dos incisos II e $\mathrm{V}$ do artigo 37 não pode se desapegar dos princípios veiculados pelo caput do mesmo artigo; e que as restrições trazidas pela dita Resolução são as mesmas já impostas pela Constituição de 1988. 


\section{A competência discricionária na Constituição de 1988}

BANDEIRA DE MELLO (2010, pp. 432-433) define a discricionariedade como liberdade dentro da lei, correspondendo à "margem de liberdade conferida pela lei ao administrador a fim de que este cumpra o dever de integrar com sua vontade ou juízo a norma jurídica, diante do caso concreto, segundo critérios subjetivos próprios, a fim de dar satisfação aos objetivos consagrados no sistema legal". ${ }^{1}$

Logo, ensina PEREIRA (2007, p. 31) a discricionariedade administrativa “(...) cingese à liberdade de escolha entre alternativas igualmente justas - indiferentes jurídicos - uma vez que a decisão a ser adotada se fundamenta em critérios extrajurídicos, não-incluídos na lei e remetidos ao julgamento subjetivo da Administração." (itálicos originais)

Cargos em comissão são de livre provimento e livre exoneração, prescindindo de concurso público. Tem-se, aqui, a outorga de competência discricionária.

$\mathrm{O}$ acórdão proferido explicita que tanto a nomeação quanto a exoneração desses cargos, conquanto livres, encontram-se balizadas pelos princípios insculpidos no caput do artigo 37 da Constituição da República vigente. Oportuna se faz a transcrição do seguinte parágrafo do voto do Ministro Celso de Mello, na $\mathrm{ADC} \mathrm{n}^{\circ} 12$ proferido:

Na realidade - e especialmente a partir da Constituição republicana de 1988 - a estrita observância do postulado da moralidade administrativa passou a qualificar-se como pressuposto de validade dos atos que, fundados ou não em competência discricionária, tenham emanado de autoridade ou órgãos do Poder Público, consoante proclama autorizado magistério doutrinário (...) (negritos originais).

Logo, embora o julgado passe ao largo dos debates que cercam o tema da discricionariedade, em última análise, firma, torna explícita a certeza de que o exercício de toda a competência administrativa, seja vinculada, seja discricionária, sujeita-se integralmente aos postulados de legalidade, impessoalidade, publicidade e eficiência.

\footnotetext{
${ }^{1}$ No mesmo sentido, JUSTEN FILHO (2005, PP. 745-746):

"A discricionariedade administrativa consiste num modo escolhido legislativamente quanto à disciplina para o exercício das competências administrativas. A discricionariedade se verifica quando a norma legislativa não contempla disciplina exaustiva no tocante à hipótese de incidência ou ao mandamento normativo, atribuindo ao titular da competência administrativa o dever-poder de formular a escolha mais adequada para satisfazer os direitos fundamentais."
} 
Há que se ter em mente, ainda, que, mesmo na seara dos concursos públicos para provimento de cargos efetivos, os respectivos editais e regulamentos trazem, não raro, itens discricionariamente estabelecidos - escolhas do gestor público - desde alguns requisitos para participar do certame até pontos das matérias das provas. Algumas etapas possibilitam, por seu modo de ser, reais possibilidades de escolhas subjetivas e idiossincráticas, que, diga-se de passagem, em nada se confundem ou se compreendem na discricionariedade. É o caso das provas orais e das entrevistas com bancas examinadoras, e, mesmo, das famigeradas "sindicâncias de vida pregressa", que prosseguem sem que ninguém ouse lhes questione a utilidade ou legitimidade.

\section{Os princípios constitucionais da Administração Pública e o nepotismo}

Em que medida a prática do nepotismo maltrata a Constituição da República?

O Relator da $\mathrm{ADC} \mathrm{n}^{\circ} 12$, em seu voto, remete à ementa do acórdão proferido no julgamento da Medida Cautelar. Naquela assentada, o Ministro Ayres Britto concluiu que as proibições contidas na Resolução 07/2005 do CNJ densificavam os princípios regentes de toda a atividade administrativa do Estado, sobretudo os da impessoalidade, da eficiência e da igualdade. Quanto à moralidade, observa:

37. É certo que todas essas práticas também podem resvalar, com maior facilidade, para a zona proibida da imoralidade administrativa (a moralidade administrativa, como se sabe, é outro dos explícitos princípios do art. 37 da CF). Mas entendo que esse descambar para o ilícito moral já é quase sempre uma consequência da deliberada inobservância dos três outros princípios citados. Por isso que deixo de atribuir a ele, em tema de nepotismo, a mesma importância que enxergo nos encarecidos princípios da impessoalidade, da eficiência e da igualdade.

Ver-se-á que os Ministros, no enfrentamento do tema, destacam sobretudo os princípios da impessoalidade e da moralidade.

\subsection{O princípio da impessoalidade e o nepotismo}

A Ministra Cármen Lúcia, em seu voto, afirma que a proibição do nepotismo advém do princípio da impessoalidade, "sendo de se lhe acoplar a moralidade administrativa". Para BANDEIRA DE MELLO (2010, p. 114), a impessoalidade se traduz na proibição de discriminações, benéficas ou detrimentosas, de favoritismo, perseguições, não podendo 
interferir na administração interesses sectários de qualquer espécie. Tal princípio, para o professor, "não é senão o próprio princípio da igualdade ou isonomia" (idem). Já FIGUEIREDO (2007, p. 63) afirma que a impessoalidade não se confunde com a igualdade, assim definindo aquela: “A impessoalidade caracteriza-se, pois, na atividade administrativa, pela valoração objetiva dos interesses públicos e privados envolvidos na relação jurídica a se formar, independentemente de qualquer interesse político."

Prossegue a saudosa professora (idem, p. 64):

A impessoalidade implica, refrise-se, o estabelecimento de regra de agir objetiva para o administrador, em todos os casos. Assim, como exemplo curial, em nomeações para determinado cargo em comissão, os critérios da escolha devem ser técnicos, e não de favoritismos ou ódios. Não pode a nomeação ser prêmio atribuído ao nomeado, como, também, não pode haver impedimento à nomeação por idiossincrasias. (grifamos)

Ao votar no julgamento da Medida Cautelar na referida ADC 12, o Ministro Cezar Peluso também preferiu versar a questão à luz do princípio da impessoalidade, que apareceria “diretamente relacionado com o controle jurídico do exercício do poder político, que, por definição, é mantido sempre por minorias”. Convém transcrever as seguintes passagens de seu voto:

Todos sabemos - e não é caso de o relembrar - que o poder discricionário, embora descrito como poder jurídico, na verdade se reduz, em ultima análise, à categoria de dever jurídico, isto é, o administrador tem de escolher, em determinadas situações, certas condutas de acordo com os princípios do ordenamento jurídico que regula a administração à qual serve. Portanto, tem de assegurar a promoção da finalidade legal dos atos administrativos. O que limita esse poder, garantindo o alcance da satisfação das necessidades e dos interesses públicos, é o princípio da impessoalidade, o qual deve guiar o administrador na escolha dos quadros, não para servir ao que se crê dono do poder, isto é, o chefe, mas para acudir às necessidades da administração pública. Daí, a exigência constitucional, como regra, do concurso público.

A impessoalidade apresenta duas dimensões em relação ao exercício desse poder: diz respeito à titularidade em si e ao exercício do poder discricionário, jungido ao interesse público e ao bem comum. Seus traços substanciais estão exatamente nesses dois alcances: primeiro, coibir o exercício do poder voltado a favorecer ou a prejudicar pessoas, e, depois, impedir o personalismo no exercício desse poder mediante atos de promoção pessoal, que a mesma Constituição proíbe de maneira peremptória. Esse princípio, é bom repetir, no primeiro aspecto, sublinha o dever de preenchimento dos 
cargos públicos sine ira et studio, significando vedação de privilégios e, também, de perseguições pessoais. E, no segundo, a autopromoção.

Na mesma vereda de destaque ao princípio da impessoalidade como fundamento da coibição do nepotismo foi o voto do Ministro Sepúlveda Pertence, também no julgamento da Medida Cautelar na ADC n ${ }^{\circ} 12$.

Destarte, a problemática das nomeações para cargos em comissão parece levantar, em primeiro lugar, a questão acerca da observância do princípio da impessoalidade no exercício da competência administrativa. Impessoalidade, em síntese, como proscrição do personalismo, do patrimonialismo, do exercício da competência administrativa para consecução de interesses privados, próprios ou de terceiros. E, como bem observa a Ministra Cármen Lúcia,

Nem precisaria haver princípio expresso - quer da impessoalidade, quer da moralidade administrativa - para que se chegasse ao reconhecimento da constitucionalidade das proibições de contratação de parentes para cargos públicos. Bastaria que se tivesse em mente a ética democrática e a exigência republicana, contidas no art. $1^{\circ}$ da Constituição, para se impor a proibição de maneira definitiva, direta e imediata a todos os Poderes da República.

Ética democrática, exigência republicana: merece, aqui, ser aberto um parêntese para recordar a noção de república apresentada por CARRAZZA (2003, pp. 48-49):

República é o tipo de governo, fundado na igualdade formal das pessoas, em que os detentores do poder político exercem-no em caráter eletivo, representativo (de regra), transitório e com responsabilidade.

\section{(...)}

A igualdade formal consiste na inexistência, para o Direito, de classes dominantes e de títulos nobiliárquicos. Numa república, não é possível a diversidade de leis aplicáveis a casos substancialmente iguais, de modo a privilegiar grupos sociais ou indivíduos. ${ }^{2}$

\footnotetext{
${ }^{2}$ CARRAZZA (2003, pp. 48-49):

“b) Fundado na igualdade formal das pessoas: numa verdadeira República não pode haver distinções entre nobres e plebeus, entre grandes e pequenos, entre poderosos e humildes. É que, juridicamente, nela não existem classes dominantes, nem classes dominadas. Assim, os títulos nobiliárquicos desaparecem e, com eles, os tribunais de exceção. Todos são cidadãos; não súditos.

De fato, a noção de República não se coaduna com os privilégios de nascimento e os foros de nobreza, nem, muito menos, aceita a diversidade de leis aplicáveis a casos substancialmente iguais, as jurisdições especiais, as isenções de tributos comuns, que beneficiem grupos sociais ou indivíduos, sem aquela 'correlação lógica entre a peculiaridade diferencial acolhida (...) e a desigualdade de tratamento em função dela conferida', de que nos fala Celso Antônio Bandeira de Mello.

Aceitando que todos os homens, indistintamente, possuem condições de pretender os mesmos direitos políticos, a República impõe o princípio da igualdade, como fulcro da organização política. E o princípio da igualdade,
} 


\subsection{O princípio da moralidade e o nepotismo}

FIGUEIREDO (2007, p. 57) conceitua o princípio da moralidade como o "conjunto de regras de conduta da Administração que, em determinado ordenamento jurídico, são consideradas os Standards comportamentais que a sociedade deseja e espera."

A moralidade administrativa é aquela extraída do próprio ambiente institucional, condicionando o manejo da competência administrativa para a consecução do bem comum. Seu conteúdo é informado pelos valores abstraídos das práticas e padrões da atividade estatal que se firmam.

O Ministro Celso de Mello, ao votar no julgamento de mérito da ação declaratória em comento, registra, de saída, que a Resolução CNJ n 07/2005 traduz emanação direta do que proscreve a própria Constituição da República, considerados, sobretudo, os postulados da impessoalidade e da moralidade. Ao desenvolver seu voto, confere relevo ao princípio da moralidade, logrando gizá-lo com propriedade:

Sabemos todos que a atividade estatal, qualquer que seja o domínio institucional de sua incidência, está necessariamente subordinada à observância de parâmetros ético-jurídicos que se refletem na consagração constitucional do princípio da moralidade administrativa, que se qualifica como valor constitucional impregnado de substrato ético e erigido à condição de vetor fundamental no processo de poder, condicionando, de modo estrito, o exercício, pelo Estado e por seus agentes, da autoridade que lhes foi outorgada pelo ordenamento normativo. Esse postulado, que rege a atuação do Poder Público, confere substância e dá expressão a uma pauta de valores éticos, nos quais se funda a própria ordem positiva do Estado.

É por essa razão que o princípio constitucional da moralidade administrativa, ao impor limitações ao exercício do poder estatal, legitima o controle de todos os atos do poder público que transgridam os valores éticos que devem pautar o comportamento dos órgãos e dos agentes governamentais, não importando em que instância de poder eles se situem. (grifos originais)

O Ministro Joaquim Barbosa também empresta relevo, na apreciação do tema, ao princípio ora examinado. Suas palavras no voto proferido no julgamento da Medida Cautelar:

como é pacífico, tem um conteúdo prevalentemente negativo: a abolição e o afastamento dos privilégios. Evidentemente, esta igualdade é formal, e não substancial.

Portanto, numa República todos os cidadãos têm a mesma dignidade social e são iguais perante a lei, sem distinção de condições sociais e pessoais." 
Por sua vez, talvez com mais ênfase ainda, impõe-se ao caso o princípio da moralidade, por aplicação direta da Constituição, sem necessidade de nenhuma intermediação legislativa, como sugerem os opositores da norma atacada.

\subsection{Impessoalidade, moralidade e proibição do nepotismo}

Observa-se nos votos proferidos pelos Ministros do Supremo Tribunal Federal, quer na apreciação da medida cautelar, quer no julgamento de mérito, uma certa perplexidade diante da questão posta, até porque envolve o exame de conceitos jurídicos indeterminados impessoalidade, moralidade. Uns emprestaram relevo ao princípio da impessoalidade como fundamento da vedação do nepotismo; outros, à moralidade; o Relator, por sua vez, entendeu que a prática do nepotismo maltrata, sobretudo, os princípios da impessoalidade, da eficiência e da igualdade.

O voto do Ministro Gilmar Mendes no julgamento da medida cautelar foi o que melhor enfrentou a questão jurídica posta na ação declaratória, abordando, metodicamente, cada problema nela embutido. Primeiro, identifica a existência de controvérsia constitucional relevante, passando pelo tema da competência do Conselho Nacional de Justiça para emanar a norma discutida, e, no tópico que abriu acerca da separação de Poderes, cuidou de examinar os princípios constitucionais envolvidos. Confiram-se os seguintes trechos do voto, verbis:

Se cabe ao CNJ zelar pelo cumprimento dos princípios da moralidade e da impessoalidade, é da sua competência fiscalizar os atos administrativos do Poder Judiciário que violem tais princípios. E não há dúvida de que os atos que impliquem a prática do nepotismo ofendem diretamente os princípios da moralidade e da impessoalidade.

A indeterminação semântica dos princípios da moralidade e da impessoalidade não pode ser um obstáculo à determinação da regra da proibição do nepotismo. Como bem anota GARCÍA DE ENTERRÍA, na estrutura de todo conceito indeterminado é identificável um 'núcleo fixo' (Begriffkern) ou 'zona de certeza', que é configurada por dados Oprévios e seguros, dos quais pode ser extraída uma regra aplicável ao caso. A vedação do nepotismo é regra constitucional que está na zona de certeza dos princípios da moralidade e da impessoalidade.

\section{A impessoalidade, a moralidade e a admissão de pessoal ao serviço público}

Inobstante a indeterminação de conceitos como impessoalidade e moralidade, é possível extraírem-se, a partir deles, regras constitucionais, como a proibição do nepotismo. 
Todos os votos proferidos pelos Ministros do Supremo Tribunal Federal aprofundam no exame desses princípios que tanta perplexidade causam mesmo na mais abalizada doutrina, e a riqueza dos debates travados na $\mathrm{ADC} \mathrm{n}^{\circ} 12$ trazem novas luzes sobre o tema maior no qual a proibição do nepotismo está encartada: o da admissão de pessoal ao serviço público.

Concursos públicos deveriam, sem qualquer exceção, ser de provas e de títulos. Entretanto, há certames que contêm a exigência de que o candidato "apresente lista de autoridades com quem haja atuado em cada um dos períodos de prática profissional, discriminados em ordem cronológica", e ainda "declaração, em ordem cronológica, dos períodos de atuação como Magistrado, Membro do Ministério Público, Advogado ou titular de função técnico-juridica, pública ou privada, com o local e a época de exercício de cada um deles, assim como a indicação das principais autoridades com as quais serviu ou esteve em contato, inclusive com os seus endereços atuais e respectivos números de telefone". 3

Pergunta-se: qual a necessidade de tais exigências? Para que um Tribunal quer saber que autoridades o candidato a juiz federal conhece ou conheceu? A utilidade da exigência é nenhuma. Além disso, qualquer concurso público é de provas e de títulos somente, jamais de relacionamentos pessoais. Aqueles candidatos que tiverem boas relações com as mais altas autoridades apresentam-se em franca vantagem em relação aos demais e cai por terra o princípio da igualdade. O maltrato à impessoalidade é gritante: através da introdução desse elemento personalista - quem o candidato conhece, conheceu, com quem tem boas ou más relações - frustra-se totalmente o escopo do concurso público e descamba-se para mazelas idênticas às ocasionadas pelo nepotismo - o uso da coisa pública para a consecução de interesses privados, egoísticos, de indivíduos ou grupos determinados, promovendo favoritismos e impedindo aprovações por idiossincrasias das mais vis.

O mesmo se pode dizer das provas orais - em que o candidato deixa de ser um desconhecido impossível de ser conhecido, logo, de ser preterido ou favorecido - para tornarse alguém, quem sabe, amado ou odiado, imposto por "padrinho" poderoso ou rejeitado por algum desafeto, da própria instituição ou estranho à ela.

Estas são reflexões surgidas neste momento, estimuladas pelo estudo dos debates travados na $\mathrm{ADC} \mathrm{n}^{\circ}$ 12. O que procuramos demonstrar, com esse exemplo, é que há vasta

\footnotetext{
${ }^{3}$ Resolução no 32, de 13 de abril de 2011, do Tribunal Regional Federal da $3^{\text {a }}$ Região. Regulamento do XVI Concurso Público para Juiz Federal Substituto da $3^{\text {a }}$ Região. Disponível http://www.trf3.jus.br/trf3r/fileadmin/docs/concurso/XVI_concurso/RES_92-PRES_de_13-04-20110001.pdf. Acesso em 6.08.2012.
} 
gama de aspectos ainda inexplorados no capítulo da admissão de pessoal à luz dos princípios constitucionais da Administração Pública, notadamente os da impessoalidade e da moralidade.

\section{Conclusão}

O julgamento da Ação Declaratória de Constitucionalidade $\mathrm{n}^{\circ} 12$, com $\mathrm{o}$ reconhecimento da proibição do nepotismo como regra constitucional, traz luzes acerca da densificação dos princípios constitucionais da moralidade e da impessoalidade administrativa: conteúdo, alcance, eficácia. Chega-se, pois, à certeza de que todos os atos administrativos, fundados ou não em competência discricionária, sujeitam-se integralmente à incidência dos ditos princípios. Não há de ser diferente na admissão de pessoal, campo que ainda apresenta prenhe de aspectos inexplorados e incompreendidos pela doutrina e jurisprudência.

\section{Referências bibliográficas}

BANDEIRA DE MELLO, Celso Antônio. Curso de Direito Administrativo. $27^{\mathrm{a}}$ edição São Paulo: Malheiros, 2010.

BRASIL. Supremo Tribunal Federal. ADC 12-DF, Pleno, Rel. Min. Carlos Britto, j. 20/08/2008, DJe-237, publ. 18/12/2009. Acesso em 19/08/2014.

BRASIL. Tribunal Regional Federal da 3ª Região. Resolução no 32, de 13 de abril de 2011. Regulamento do XVI Concurso Público para Juiz Federal Substituto da $3^{\text {a }}$ Região. Disponível em:

<http://www.trf3.jus.br/trf3r/fileadmin/docs/concurso/XVI_concurso/RES_92-PRES_de_1304-20110001.pdf $>$. Acesso em 6.08.2012.

CARRAZZA, Roque Antônio. Curso de Direito Constitucional Tributário; $19^{a}$ edição. São Paulo: Malheiros, 2003.

FIGUEIREDO, Lúcia Valle. Curso de Direito Administrativo. $9^{\mathrm{a}}$ edição São Paulo: Malheiros, 2007.

JUSTEN FILHO, Marçal. Curso de Direito Administrativo. São Paulo: Saraiva, 2005. 
PEREIRA, Flávio Henrique Unes. Conceitos Jurídicos Indeterminados e Discricionariedade Administrativa à Luz da Teoria da Adequabilidade Normativa. In: Revista CEJ. Conselho da Justiça Federal, Brasília, n. 36, pp.30-38, jan/mar 2007.

Artigo recebido em 20 de março de 2014. Artigo aprovado para publicação em 27 de maio de 2014.

DOI: $10.11117 / 1982-4564.07 .08$ 